\title{
CENÁRIOS DA AGRESSÃO NO TRÂNSITO: A PERCEPÇÃO QUE AS PESSOAS TÊM DE UM MOTORISTA AGRESSIVO ${ }^{1}$
}

\author{
Valdiney V. Gouveia* \\ Pollyane K. C. Diniz \\ Emerson Diógenes de Medeiros" \\ Jane Palmeira Nóbrega Cavalcanti ${ }^{\mathfrak{\infty}}$ \\ Rildésia S. V. Gouveia ${ }^{\circledR}$
}

\begin{abstract}
RESUMO. Este estudo objetivou conhecer a percepção que as pessoas têm de um motorista agressivo e as causas atribuídas ao seu comportamento. Participaram 389 estudantes universitários, a maioria mulheres (53,8\%). Estes leram os cenários de agressão no trânsito, indicando sua opinião acerca do motorista agressor (civilidade e rusticidade) e de suas motivações (interna e externa) para agir com agressividade. Posteriormente, responderam o Questionário de Agressão de Buss-Perry e a perguntas demográficas. Os resultados indicaram o motorista agressor percebido como pessoa de mais rusticidade do que delicadeza e urbanidade; contudo, na percepção dos participantes, o comportamento deste foi considerado conforme o tipo de motivação. Os respondentes com maior pontuação em agressão verbal e agressão física tenderam a minimizar a conotação negativa do comportamento do motorista agressor. Finalmente, seu comportamento foi julgado como mais internamente determinado quando se tratava de alguém do sexo masculino e jovem. Estes resultados são consistentes com os da literatura.

Palavras-chave: trânsito, agressão, motivação.
\end{abstract}

\section{AGGRESSION SCENES IN ROAD TRAFFIC: PEOPLE'S PERCEPTION OF AN AGGRESSIVE DRIVER}

\begin{abstract}
People's perception of an aggressive driver and the causes attributed to his/her behavior are provided. Participants, 389 undergraduate students, most of them women (53.8\%), interpreted aggression scenes in road traffic and revealed their opinion on the aggressive driver (civility and rudeness) and on the driver's motivations (internal and external motivation) to behave with such aggressiveness. Participants filled the Buss-Perry Aggression Questionnaire and demographic questions. Results indicated that the aggressive driver was perceived as demonstrating more rudeness than civility. In the participants' perception, however, the driver's aggressive behavior did not differ from the type of motivation. Participants with high scores in verbal aggression and physical aggression tended to minimize the negative connotation of the driver's aggressive behavior. Finally, the drive's aggressive behavior was judged as more internally determined when male and young. Findings are consistent with the literature.
\end{abstract}

Key words: Traffic, aggression, motivation.

\section{ESCENARIOS DE AGRESIÓN EN EL TRÁNSITO: LA PERCEPCIÓN QUE LAS PERSONAS TIENEN DE UN CONDUCTOR AGRESIVO}

RESUMEN. Este estudio buscó conocer la percepción que las personas tienen de un conductor agresivo y las causas atribuidas a su conducta. Participaron 389 estudiantes universitarios, en su mayoría mujeres (53.8\%). Ésos leyeron escenarios de agresión en el tránsito, indicando su opinión con respecto al conductor agresor (civilidad y rusticidad) y sus motivaciones (interna y externa) para accionar con agresividad. Posteriormente, contestaron al Cuestionario de Agresión de Buss-Perry y a

\footnotetext{
Apoio: CNPq e CAPES.

* Doutor em Psicologia Social. Professor Adjunto da Universidade Federal da Paraíba.

\# Psicólogo. Mestrando(a) em Psicologia Social na Universidade Federal da Paraíba.

II Psicólogo. Doutorando em Psicologia Social na Universidade Federal da Paraíba.

æ Mestra em Psicologia Social.

Æ Psicóloga. Doutoranda em Psicologia Social na Universidade Federal da Paraíba
} 
preguntas demográficas. Los resultados indicaron que el conductor agresor fue percibido como una persona de más rusticidad, que delicadeza y civilidad; sin embargo, en la percepción de los participantes, el comportamiento de éste fue considerado conforme con el tipo de motivación. Los respondientes con mayor puntaje en agresión verbal y agresión física tuvieron la tendencia a minimizar la connotación negativa de la acción del conductor agresor. Finalmente, su conducta fue juzgada como más internamente determinada cuando se trataba de un varón y joven. Éstos resultados son consistentes con la literatura.

Palabras-clave: tránsito, agresión, motivación.

A cultura compreende, seguramente, a construção individual e social do homem, mas também é o espelho da sem-razão humana. Cada dia mais os povos parecem caminhar em direção ao individualismo, selvagem, egoísta e consumista (Lipovetsky, 1986). Importam, neste cenário que se apresenta, a privacidade, o exibicionismo e o direito individual, mascarando ou suplantando o bem comum. Aspectos tão pragmáticos como o trânsito e o carro adquirem novas conotações, refletindo desejos das pessoas de serem indivíduos, individualizadas e únicas. Por exemplo, Arsênio (2003) observa que "o automóvel e as motocicletas são cada vez menos utilizados como meio de transporte e cada vez mais como símbolos sociais que, além de expressarem seu valor econômico, são também formas de poder, prestígio, força, habilidade, destreza, sucesso, beleza, juventude etc." (p. 49).

De fato, após a Segunda Guerra Mundial o automóvel tornou-se um dos fenômenos de massa em todo o mundo, embora de alcance limitado. Constituise, assim, em uma espécie de "artigo de consumo", evidenciando o status social e econômico do proprietário. Sem dúvida, esta concepção ganhou respaldo e foi impulsionada pela publicidade de economias capitalistas, exercendo na maioria dos países forte influência nos comportamentos e valores das pessoas. Incessantemente, as propagandas têm destacado a mobilidade individual e a prosperidade material sem precedentes, ademais de associarem anúncios de carros caros e velozes com virilidade (Marín \& Queiroz, 2000).

Neste contexto de individualidades, com a exacerbação do consumismo e a busca pelo diferente e único, procurando refletir o poder e o prestígio, o carro já não é mais um meio de transporte. Constituise em objeto ímpar, talvez um cartão de visita ou um troféu pelo sucesso nos negócios. Portanto, demandarse-iam normas e leis diferentes de trânsito: os limites de velocidade precisam ser quebrados para demonstrar toda a potência do utensílio; os pedestres devem dar a vez à importante aquisição; e as calçadas muito servem como vitrines. Esse fascínio que o automóvel exerce sobre o motorista, permitindo-lhe experimentar sentimentos de grandeza e fantasia de onipotência, forja a ilusão de controle e estimula o aumento de velocidade nas ruas e estradas e, conseqüentemente, leva a maior risco de envolvimento em acidentes de trânsito (Groeger \& Rothengatter, 1998; Marín \& Queiroz, 2000). Como assevera Arsênio (2003), distorções desta natureza não tardam em potencializar a agressividade do indivíduo, logo convertida em violência no trânsito.

O tema da agressividade (individual) e violência (fenômeno mais coletivo) no trânsito tem ocupado pesquisadores de diversos países (Hennessy \& Wiesenthal, 2001; Miles \& Johnson, 2003; Parker, Lajunen \& Summala, 2002; Rozestraten, 2003). Tem sido particularmente estudado no que diz respeito aos acidentes de trânsito. Por exemplo, na revisão realizada por Rozestraten (1988), entre os fatores humanos que levam ao acidente estão a forma agressiva de dirigir e as brigas do marido com sua esposa. A propósito, é provável que a maior tendência agressiva dos homens (Harris, 1996; Lahey et al., 2000; Uzzell \& Muckle, 2005) seja um fator que o predispõe mais do que às mulheres a se envolverem em acidentes de trânsito (Marín \& Queiroz, 2000). Contudo, o sexo do motorista não é a única variável que potencializa maior velocidade e conseqüente acidente de trânsito. Sua idade tem sido identificada como um fator preponderante. Por exemplo, Fildes, Rumbold e Leening (1991) indicam que motoristas jovens geralmente viajam em velocidade bastante superior à daqueles mais velhos (ver também Uzzell \& Muckle, 2005), e que há uma relação diretamente proporcional entre o ano do veículo e a escolha da velocidade com que se dirige.

Apesar da importância de conhecer os múltiplos fatores que podem influenciar a agressividade do motorista, a velocidade com que dirige e seu conseqüente envolvimento em acidentes, parece igualmente relevante estudar a percepção ou o juízo que as demais pessoas fazem a respeito do motorista agressor. Conhecer como as pessoas percebem situações cotidianas de agressão no trânsito pode ajudar a compreender seus próprios comportamentos em situações semelhantes, quando tiverem que se deparar com eventos reais. Além disso, pesquisar acerca da percepção dos observadores, potenciais 
motoristas, tem igualmente a vantagem de evitar um viés de resposta bastante presente em pesquisas sobre trânsito quando se empregam escalas e questionários: a desejabilidade social, isto é, a tendência em apresentar-se como adequado, correto, justo e cumpridor das normas e leis (Lajunen, Corry, Summala \& Hartley, 1997).

A propósito do juízo que fazem as pessoas acerca de um mesmo evento no trânsito, Gabany, Plummer e Grigg (1997) estudaram a compreensão de diferentes grupos sobre velocidade no trânsito. Neste sentido, constataram que a gratificação do ego proporcionada pelo veículo é mais indicada pelos homens como causa potencial da velocidade. Por sua vez, os mais jovens apontam a tendência a assumir riscos como sua principal causa, enquanto as mulheres indicam a pressa.

Em resumo, as situações de trânsito envolvem elementos complexos (por exemplo, características do veículo, condições das estradas, variáveis do motorista; ver Marín \& Queiroz, 2000; Rozestraten, 1988), alguns deles interagindo. O resultado, muitas vezes, se expressa através de comportamentos agressivos, que demandam as mais diversas reações, desde o revide até a reprovação. Os cenários do trânsito têm significados também diversos para os observadores, que formam percepções e juízos com base nos personagens ou aspectos de tais situações, mas também em suas características demográficas.

Em face do que antes se comentou, o objetivo principal da presente pesquisa foi conhecer como as pessoas percebem alguém que agride em situação hipotética de trânsito, considerando três atributos do motorista agressor: sexo, idade e tipo de carro que conduz. Pretendeu-se, especificamente, conhecer como os observadores definem pessoalmente $o$ agressor e a percepção que têm acerca dos motivos que o levaram a agredir. Finalmente, buscar-se-á conhecer se o próprio traço de agressão dos observadores pode influenciar no seu juízo acerca do motorista agressor.

\section{MÉTODO}

\section{Delineamento}

Realizou-se uma pesquisa quase-experimental, considerando um delineamento fatorial 2 (sexo do agressor: masculino vs. feminino) $\mathrm{x} 2$ (idade do agressor: 20 anos - jovem vs. 60 anos - idoso) x 2 (carro do agressor: fusca 1976 - velho vs. Ranger 2005 - novo). As oito condições experimentais foram operacionalizadas através de estórias. Incluíram-se também perguntas acerca do grau de agressão dos participantes, de suas opiniões em relação ao agressor e suas motivações para agir com agressividade.

\section{Amostra}

Participaram desta pesquisa 389 estudantes de 19 cursos (por exemplo, Administração, Ciências da Computação, Direito, Engenharia Mecânica, Medicina, Psicologia) de uma universidade pública de João Pessoa. A maioria foi do sexo feminino $(53,8 \%)$, considerando-se de classe socioeconômica média $(62,7 \%)$, sendo que suas idades variaram de 16 a 58 $\operatorname{anos}(M=22,4 ; D P=4,84)$.

\section{Instrumentos}

Os participantes receberam uma folha impressa frente-verso, onde figuravam os seguintes conteúdos:

Cenários de agressão no trânsito. Conforme as oito condições experimentais, criaram-se estórias através das quais foram manipuladas as variáveis de interesse. Cada participante deveria ler com atenção a estória que lhe era apresentada e em seguida responder a perguntas específicas acerca dela. Um exemplo destas estórias é mostrado a seguir (o leitor interessado poderá solicitar dos autores as demais estórias):

Antônio trafega pela Av. Epitácio Pessoa no seu veículo. Ele se depara com um sinal vermelho, sendo obrigado a parar. João é um senhor de 60 anos de idade, que pára seu carro, um fusca 1976, logo em seguida ao de Antônio. O sinal fica verde e o carro de Antônio não sai do lugar. Sr. João, por isso, começa a buzinar. Transcorridos alguns instantes, Antônio continua sem sair do lugar e Sr. João passa a gritar com ele e a xingá-lo, deixando-o nervoso.

Inicialmente, perguntou-se em que medida os participantes consideravam provável $(\mathbf{0}=$ Nada provável a $\mathbf{1 0 0}=$ Muito provável) o tipo de cena descrita ter ocorrido de fato. Posteriormente, procurou-se conhecer como percebiam o motorista agressor, considerando oito pares de adjetivos: egoísta-altruísta, errado-certo, educado-grosseiro, adequado-inadequado, humilde-prepotente, irracionalracional, irresponsável-responsável e pacíficoviolento. Estes se localizavam em lados opostos, coincidindo com os valores extremos da escala de resposta: 1 e 5, respectivamente. Finalmente, avaliaram-se seis razões percebidas como motivadoras da ação de agredir: é uma pessoa mal-humorada, estava atrasado/a para o trabalho, é uma pessoa 
metida, precisava atender uma urgência, quer ser o/a dono/a do mundo e estavam buzinando atrás dele/a. Os participantes deveriam indicar quanto cada uma destas motivações era provável, considerando a escala de resposta de cinco pontos, cujos extremos eram $\mathbf{1}$ (Nada provável) e 5 (Totalmente provável).

Medida de componentes da agressão. Empregouse o Questionário de Agressão de Buss-Perry (Buss \& Perry, 1992), cuja versão brasileira consta de 26 itens que, teoricamente, avaliam a agressão em quatro dimensões, a saber (Gouveia, Chaves, Peregrino, Branco \& Gonçalves, 2006): agressão física (Alfa = 0,65; por exemplo, Se alguém me bater, eu o bato de volta; Uma vez ou outra não consigo controlar a vontade de bater em outra pessoa), agressão verbal (Alfa $=0,52$; Não consigo ficar calado/a quando as pessoas discordam de mim; Constantemente me vejo discordando das pessoas), raiva (Alfa $=0,71$; Alguns amigos dizem que sou cabeça quente; Fico furioso/a facilmente, mas também me acalmo rapidamente) e hostilidade (Alfa = 0,62; Quando as pessoas são muito gentis, duvido de suas intenções; Desconfio de pessoas estranhas que são amigáveis demais comigo). As respostas são dadas em escala de cinco pontos, tipo Likert, com os seguintes extremos: 1 = Discordo totalmente e $\mathbf{5}=$ Concordo totalmente.

Finalmente, perguntou-se aos participantes se tinham a Carteira Nacional de Habilitação, se já haviam brigado no trânsito e de quem julgavam ser a culpa, bem como acerca de quem dirige melhor: homens vs. mulheres, jovens vs. pessoas maduras, e ricos $v s$. pobres. Indicaram ainda informações demográficas: idade, sexo e classe econômica.

\section{Procedimento}

A participação dos respondentes se deu individualmente, porém em ambiente coletivo de sala de aula. Uma vez obtida a permissão dos professores dos cursos correspondentes, os responsáveis pela aplicação dos instrumentos se apresentavam em sala de aula com o fim de solicitar a colaboração dos estudantes. Estes foram informados sobre os propósitos da pesquisa, identificada como objetivando conhecer como as pessoas pensam e agem no seu diaa-dia. Procurou-se indicar que sua participação seria voluntária, devendo responder individualmente aos questionários. Enfatizou-se que não existiam respostas certas ou erradas e que estas seriam mantidas no anonimato, tratadas de forma estatística no conjunto. Foram necessários 10 minutos para concluir sua participação.

\section{RESULTADOS}

\section{Habilitação para conduzir e indicadores de agressão}

Quase a metade dos participantes do estudo indicou possuir Carteira Nacional de Habilitação $(48,3 \%)$. Inquiridos a responder quem dirigia melhor entre três pares apresentados: (a) homens vs. mulheres, (b) jovens $v s$. pessoas maduras e (c) ricos $v s$. pobres, eles opinaram majoritariamente não haver diferença entre homens e mulheres (56,9\%), embora $29,2 \%$ disseram que os homens dirigem melhor; 51,5\% indicaram que as pessoas maduras dirigem melhor, apesar de 41,8\% terem afirmado não haver diferença; e foi majoritário o grupo dos que informaram não haver diferença entre ricos e pobres no que se refere à habilidade para conduzir $(88,5 \%)$.

Os participantes também foram perguntados se já brigaram no trânsito, sendo que $13,5 \%$ responderam afirmativamente. Destes, apenas 2,5\% se identificaram como únicos culpados; $54,4 \%$ opinaram que o culpado foi o outro; e $43 \%$ admitiram compartilhar a culpa. Por outro lado, quando perguntados acerca de qual a probabilidade de a cena (estória) descrita ter ocorrido de fato, 9,5\% indicaram que a chance era de $30 \%$ ou menos; os que opinaram que esta poderia chegar a $50 \%$ alcançaram a quarta parte dos respondentes $(25,3 \%) ; 67,3 \%$ opinaram que esta cena teria $70 \%$ ou mais de chance de ter ocorrido; e, finalmente, os que sugeriram absoluta possibilidade de a cena indicada ter ocorrido ( $100 \%$ de chance) perfizeram $21,8 \%$ dos respondentes.

Admitindo-se que as pontuações de agressão têm uma distribuição normal ( skewness $=0,31$; kurtosis $=$ 0,36), considerando ainda sua amplitude teórica (26130), a mediana esperada seria de 52 pontos. Tomando este valor como referência e calculando um teste $t$ para medidas repetidas (emparelhadas), observou-se que os participantes deste estudo apresentaram uma média de agressão $(M=66,6, D P=$ 13,74) que foi estatisticamente superior, $t(370)=$ $20,51, p<0,001$.

\section{Percepção de atributos do motorista agressor e de sua motivação}

Inicialmente, considerou-se a medida de atributos do motorista agressor, realizando uma análise fatorial exploratória (Componentes Principais, CP), definindo a rotação varimax $[K M O=0,82$; Teste de Esfericidade de Bartlett, $\left.\chi^{2}(28)=639,58, p<0,001\right]$. Dois componentes emergiram com eigenvalues superiores a 1, explicando conjuntamente $54,7 \%$ da variância total, conforme descritos na Tabela 1 a seguir. 
Tabela 1. Estrutura Fatorial da Medida de Atributos do Motorista Agressor

\begin{tabular}{lccc}
\hline & \multicolumn{3}{c}{ Componentes } \\
\cline { 2 - 4 } Conteúdo dos Itens & I & II & $\boldsymbol{h}^{2}$ \\
\hline Racional / Irracional & $0,75^{*}$ & $-0,15$ & 0,58 \\
Responsável / Irresponsável & $0,74^{*}$ & $-0,20$ & 0,59 \\
Certo / Errado & $0,68^{*}$ & $-0,02$ & 0,46 \\
Altruísta / Egoísta & $0,59 *$ & $-0,32$ & 0,45 \\
Injusto / Justo & $-0,48^{*}$ & 0,39 & 0,38 \\
Violento / Pacífico & $-0,03$ & $0,79 *$ & 0,62 \\
Grosseiro / Educado & $-0,08$ & $0,77^{*}$ & 0,60 \\
Prepotente / Humilde & $-0,32$ & $0,63 *$ & 0,50 \\
Paciente / Impaciente & $\mathbf{0 , 4 6}$ & $-0,53 *$ & 0,49 \\
Inadequado / Adequado & $-0,39$ & $0,53^{*}$ & 0,42 \\
\hline Número de Itens & 5 & 5 & \\
Valor Próprio & 2,63 & 2,49 & \\
\% Variância Total & 26,3 & 24,9 & \\
Alfa de Cronbach & 0,73 & 0,74 & \\
\hline
\end{tabular}

Notas. * saturação mínima considerada para interpretação do componente, $|0,40|$. A saturação em negrito, embora acima do valor pré-determinado, não se considerou para a composição do componente.

O primeiro componente reuniu cinco itens com saturações variando de $-0,48$ (injusto - justo) a 0,75 (racional - irracional). Seu eigenvalue foi de 2,63, explicando $26,3 \%$ da variância total. A partir da leitura do conteúdo dos seus itens, decidiu-se defini-lo como civilidade, cuja consistência interna (Alfa de Cronbach) foi de 0,73. No caso do segundo componente, este também ficou formado por cinco itens, cujas saturações variaram de 0,52 (inadequado adequado) a 0,79 (violento - pacífico). Este apresentou eigenvalue de 2,49 , sendo responsável pela explicação de $24,9 \%$ da variância total. Claramente pode ser nomeado de rusticidade, apresentando Alfa de Cronbach de 0,74. Cabe aqui um comentário acerca do item "paciente - impaciente", o qual foi considerado no segundo componente; isso se deveu a sua maior saturação neste componente e ao sentido subjacente que apresenta, denotando o sentido de irritabilidade que é consistente com a concepção de agressão e rusticidade. As pontuações médias nestes componentes se correlacionaram inversamente $(r=$ $0,49, \underline{\mathrm{p}}<0,001)$, sendo que quando ambas foram comparadas o motorista agressor foi percebido como apresentando mais rusticidade $(M=4,1, D P=0,77)$ do que civilidade $(M=2,0, D P=0,79), t(353)=$ $29,98, p<0,001$.

Um procedimento similar ao anterior foi adotado para a medida de motivação do motorista agressor, isto é, realizou-se uma análise fatorial exploratória (CP) com seus seis itens, adotando-se igualmente a rotação varimax $[K M O=0,60$; Teste de Esfericidade de Bartlett, $\left.\chi^{2}(15)=314,80, p<0,001\right]$. Foi possível identificar dois componentes com eigenvalues maiores que 1 , que conjuntamente explicaram $57,9 \%$ da variância total, como se descreve na Tabela 2.

Tabela 2. Estrutura Fatorial da Medida de Motivação do Motorista Agressor

\begin{tabular}{lccc}
\hline \multirow{2}{*}{ Conteúdo dos Itens } & \multicolumn{3}{c}{ Componentes } \\
\cline { 2 - 4 } Quer ser dono do mundo & I & II & $h^{2}$ \\
É uma pessoa metida & $0,79^{*}$ & $-0,13$ & 0,64 \\
É uma pessoa mal-humorada & $0,69^{*}$ & 0,11 & 0,61 \\
Precisava atender uma urgência & 0,01 & $0,84^{*}$ & 0,71 \\
Estava atrasado para o trabalho & 0,10 & $0,82^{*}$ & 0,68 \\
Estavam buzinando atrás dele & $-0,17$ & $0,56^{*}$ & 0,34 \\
\hline Número de Itens & 3 & 3 & \\
Valor Próprio & 1,75 & 1,72 & \\
\% Variância Total & 29,2 & 28,7 & \\
Alfa de Cronbach & 0,64 & 0,60 \\
\hline
\end{tabular}

Notas. * saturação mínima considerada para interpretação do componente, $10,40 \mid$.

$\mathrm{O}$ primeiro componente reuniu três itens, com saturações variando de 0,69 (É uma pessoa malhumorada) a 0,79 (Quer ser o dono do mundo), sendo evidente sua denominação: motivação interna atribuída ao comportamento agressivo do motorista. Este componente apresentou valor próprio de 1,75, explicando $29,2 \%$ da variância total, com Alfa de Cronbach de 0,64. No caso do segundo componente, este reuniu igualmente três itens, cujas saturações variaram de 0,56 (Estavam buzinando atrás dele) a 0,84 (Precisava atender uma urgência). A leitura do conteúdo destes itens não deixa dúvidas a sua interpretação: compreende motivação externa atribuída ao comportamento agressivo do motorista. Seu valor próprio foi 1,72 , sendo responsável pela explicação de $28,7 \%$ da variância total, apresentando Alfa de Cronbach de 0,60. Não houve diferença estatística do tipo de motivação atribuído ao comportamento agressivo do motorista $(t<1)$.

\section{Atributos do motorista agressor e a percepção produzida nos observadores}

Através de um delineamento fatorial $2 \times 2 \times 2$, foram manipulados três atributos do motorista agressor: sexo, idade e tipo de carro. A propósito, realizou-se uma MANOVA para conhecer o efeito principal e de interação destes fatores em relação a dois grupos de variáveis dependentes (critérios): (1) percepção que as pessoas têm do motorista agressor. Não se constatou efeito principal ou de interação de qualquer um dos três fatores $(F<2)$; e (2) motivações atribuídas ao motorista agressor. Os testes 
revelaram efeito principal do sexo do motorista agressor [Lambda de Wilks $=0,98, F(2,356)=3,26, p<0,05$ ], além de efeito de interação entre seu sexo e sua idade [Lambda de Wilks $=0,98, F(2,356)=3,40, p<0,05]$. O sexo do agressor foi preponderante para explicar a motivação externa, $F=6,34, p<0,05$. Especificamente, atribuem-se mais motivações externas para os motoristas do sexo feminino $(M=3,3)$ do que para aqueles do sexo masculino $(M=3,1), p<0,05$. Quanto ao efeito de interação, este foi estatisticamente significativo em relação à motivação interna $(F=5,12, p<0,05)$, sendo maior a média quando o motorista agressor era do sexo masculino e tinha 20 anos $(M=3,3)$ do que quando era homem com 60 anos ou mulher com 20 anos ( $M=3,1$ para ambos).

Finalmente, o efeito principal do tipo de carro do motorista agressor não foi significativo, mas é bastante coerente com o que se esperaria no caso da motivação interna $(F=3,24, p=0,07)$. Concretamente, o motorista que está em um carro novo de luxo (Ford Ranger 2005) é percebido como apresentando mais motivações internas para agir agressivamente $(M=$ $3,3)$ do que aquele que é descrito como estando em um carro popular e velho (Fusca 1976; $M=3,1$ ).

\section{Agressão do Observador e sua Percepção da Situação e do Motorista Agressor}

Inicialmente, correlacionaram-se os fatores de agressão e a pontuação total da medida correspondente com a percepção que os participantes têm acerca de qual seria a probabilidade de o evento descrito ter ocorrido de fato. Neste caso, unicamente as pontuações em agressão física apresentaram correlação significativa, porém baixa $(r=-0,11, p<0,05)$. Isto sugere que quanto maior agressão física menor a probabilidade atribuída à ocorrência do evento.

As pontuações dos participantes no Questionário de Agressão de Buss-Perry foram também correlacionadas com a percepção que estes revelaram do motorista agressor e de sua motivação para apresentar tal comportamento. A pontuação total de agressão se correlacionou unicamente com a percepção do motorista como apresentando civilidade $(r=0,12, p<0,05)$, indicando que apresentar em maior medida esta predisposição poderia levar a perceber o motorista como pouco racional. No caso dos fatores específicos de agressão, constatou-se o seguinte: a agressão verbal se correlacionou com a percepção do motorista como civilidade $(r=0,13, p<$ $0,05)$ e rusticidade $(r=-0,11, p<0,05)$, e a atribuição de motivação externa $(r=0,11, p<0,05)$; a agressão física apresentou correlação com a percepção civilidade $(r=0,13, p<0,05)$ e rusticidade $(r=-0,18$, $p<0,01)$; e, finalmente, os fatores de raiva $\mathrm{e}$ hostilidade não se correlacionaram com as variáveis de percepção e motivação do motorista.

\section{DISCUSSÃO}

A agressividade tem sido tema recorrente nos dias de hoje, provavelmente por sua presença constante na mídia. Esta tem revelado diariamente, nos documentários, filmes e programas de televisão, o "espetáculo" da agressividade humana (Rodrigues, Jablonski \& Assmar, 2000). Procurou-se aqui contribuir para entender este fenômeno em um âmbito restrito, porém não menos preponderante da vida das pessoas nos dias de hoje: o trânsito. Sabe-se que os motoristas com maior risco de acidentes apresentam indicadores de agressividade em dimensão mais elevada, assim como dificuldades de controlar seus impulsos agressivos (Almeida, 2003). Concretamente, o objetivo da presente pesquisa foi conhecer como as pessoas percebem alguém que agride em situação hipotética de trânsito e a que atribuem seu comportamento. De modo específico, pretendeu-se conhecer se esta percepção poderia ser explicada por atributos do motorista agressor e dos próprios respondentes, observadores da situação.

Apesar do antes comentado, não poderiam deixar de ser mencionados fatores que potencialmente limitam os achados previamente descritos. Inicialmente, há que se ponderar que não se tratou de situação real de trânsito, mas de cenários ou estórias que podem apenas suscitar aquelas que seriam as respostas concretas e reais. Além disso, não foram estudadas todas as dimensões do comportamento agressivo, mas apenas uma: agressão verbal (Buss \& Perry, 1992), que costuma ser menos ameaçadora e mais corriqueira. Os respondentes também não foram diretamente implicados nas estórias, mas se posicionaram enquanto observadores. Por exemplo, talvez a percepção a respeito do comportamento do motorista agressor tivesse sido outra se fosse alguém próximo a ele (Gouveia, Clemente, Vidal \& Martinez, 2000). Finalmente, foram incluídos na pesquisa apenas estudantes universitários, que não representam a população de motoristas. Estas considerações, não obstante, não invalidam os resultados descritos anteriormente, que passam a ser considerados.

\section{Principais resultados}

No geral, percebeu-se que os participantes do estudo não diferenciam as pessoas em termos da habilidade para conduzir em função do sexo e poder econômico; porém o fazem quanto à idade, indicando que os mais velhos, isto é, as pessoas maduras, 
dirigem melhor. É possível que isso se deva ao fato de os jovens, comprovadamente, conduzirem em maior velocidade, e que isso seja percebido como uma forma de assumir riscos ou buscar sensações (Gabany et al., 1997).

Quanto a brigar no trânsito, uma razão de 1,4:10 respondentes disse ter apresentado este comportamento. Contudo, provavelmente devido ao grau de desejabilidade social em responder nas circunstâncias perguntadas (Lajunen et al., 1997), menos de 3\% deste total assumiram a culpa exclusiva; mais da metade colocou a culpa no outro condutor. Estes números parecem alarmantes, mas espelham uma característica da amostra considerada, cuja tendência à agressão é evidente, segundo a medida de Buss e Perry (1992). Porém, salienta-se aqui que suas pontuações não foram comparadas em função de uma norma, mas de um ponto mediano teórico das pontuações totais. Seja como for, um aspecto parece preocupante: mais de 2/3 dos participantes do estudo relataram que a probabilidade de a cena de agressão no trânsito ter ocorrido seria de ao menos $70 \%$. Este dado ressalta a banalidade das cenas de violência e agressão na vida cotidiana, sugerida por Rodrigues et al. (2000).

As dimensões de civilidade e rusticidade mostraram-se suficientes para apreender a percepção que as pessoas têm do motorista agressor. Coerentemente, este foi percebido como apresentando comportamentos que evidenciavam mais rusticidade do que civilidade. Não obstante, a magnitude com que as pessoas endossaram uma ou outra percepção variou em função do seu traço de agressão. Concretamente, os indivíduos com maior pontuação em agressão verbal e agressão física tenderam a "apoiar" o motorista agressor e a "minimizar" a conotação negativa do seu comportamento, isto é, inclinaram-se mais a interpretá-lo como indicador de civilidade e não rusticidade. No caso dos que pontuaram mais em agressão verbal, o comportamento de agressão do motorista foi atribuído a motivações externas, eximindo-o de responsabilidade por seus atos. É possível que este processo de percepção resulte da presumível identificação do observador com o motorista que apresenta um traço que o caracteriza (agressão verbal), o que o faz adotar estratégias de atribuição similar à que adotaria caso tivesse que indicar um motivo para sua própria conduta (Gouveia et al., 2000).

Quanto ao tipo de atribuição de motivo para o comportamento do motorista agressor, as dimensões clássicas de motivação interna e motivação externa foram suficientes para representar as respostas dos participantes. Claramente, quando este motorista era do sexo feminino, julgava-se como mais externamente determinado seu comportamento de agredir. Contrariamente, quando se tratava de um motorista do sexo masculino e jovem, atribuía-se seu comportamento de agredir mais a motivações internas. Estas mesmas motivações são atribuídas quando o motorista agressor conduz um carro novo de luxo. Portanto, ser jovem, do sexo masculino e conduzir um carro novo de luxo sugere comportamentos intrinsecamente agressivos, talvez resultado da visão do jovem motorista de classe média-alta, caracterizado como "buscador de aventuras", cujo carro compreende mais um artigo de luxo que precisa ser exibido (Marín \& Queiroz, 2000), um símbolo social que reflete poder, prestígio, força, habilidade, destreza, sucesso, beleza e juventude (Arsênio, 2003).

\section{Pesquisas Futuras}

De acordo com Rozestraten (2003), qualquer acidente de trânsito é um ato de violência. É preocupante que, ainda segundo este autor, $85 \%$ dos acidentes de trânsito são devidos a fatores humanos. Uma das causas principais do comportamento agressivo e violento no trânsito pode ser a frustração, como ter que parar a cada semáforo, sendo impedido de prosseguir ou, o que pode ser mais instigador, perceber que o motorista da frente não dá partida no seu veículo, mesmo estando o semáforo em verde; porém esta não é a causa única. Portanto, requerer-se-ia conhecer que outros fatores podem explicar a agressão dos motoristas no trânsito e como esta pode ser enfrentada pelos demais, o que tornaria, provavelmente, mais orientados os programas de políticas públicas que visam reduzir o montante de acidentes e desentendimentos nas vias públicas de tráfego.

A linha de pesquisa aqui considerada parece frutífera. Contudo, cumpre explorar contextos diversos (por exemplo, dimensões de agressão) e avaliar o comportamento do motorista agredido. É possível que uma agressão verbal no trânsito se transforme em um ato físico de agressão em razão da resposta dada por quem sofre a provocação. Neste caso, provavelmente, seu comportamento também poderá depender de suas características pessoais (por exemplo, sexo, idade) e seus traços de personalidade (por exemplo, agressão, neuroticismo, extroversão). Esforços futuros deveriam ter estes fatores em consideração. Finalmente, sugerese ainda avaliar como os próprios respondentes da pesquisa indicam reagir às situações fictícias de agressão, bem como avaliar pormenorizadamente seu histórico de envolvimento em acidentes e enfrentamentos no trânsito. 


\section{CONSIDERAÇÕES FINAIS}

Caberia indagar qual o papel dos psicólogos que atuam nos departamentos estaduais de trânsito ou a eles prestam serviços. Já são anos de informações acumuladas, mas poucos dados realmente registrados. Testes de atenção, de diversos tipos, têm ocupado os aspirantes a condutor, mas pouco é sabido sobre sua eficácia, por exemplo, para predizer infrações que requeiram esta habilidade cognitiva (por exemplo, avançar o semáforo em vermelho, não perceber uma placa de proibido estacionar). Se a agressão é um fator importante na explicação de acidentes de trânsito (Almeida, 2003), deveria merecer a atenção dos profissionais preocupados em avaliar a capacidade do aspirante a condutor. A população geral ainda hesita em confiar no trabalho do psicólogo perito examinador de trânsito (Gouveia et al., 2002), talvez por não perceber que sua avaliação tenha conexão com os fatos em situação real de trânsito. Neste sentido, parece evidente que cada dia mais os psicólogos devam ter a premissa na escolha dos testes, cabendo-lhes fundamentar sua necessidade. É igualmente preciso repensar o processo de avaliação. Se, por exemplo, a agressão é um traço de personalidade e este é um construto duradouro, resistente a mudanças, por que permitir que uma pessoa reprovada em um teste possa prontamente se submeter à avaliação psicológica? Esta é uma situação ao menos inconsistente com o que tem sido ensinado nas faculdades de Psicologia.

\section{REFERÊNCIAS}

Almeida, N. D. V. (2003). Circulação humana e subjetividade. Em A. C. R. Tupinambá (Org.), Estudos de psicologia do trânsito (pp. 62-74). Fortaleza: Expressão Gráfica.

Arsênio, J. (2003). Violência no trânsito I. Em A. C. R. Tupinambá (Org.), Estudos de psicologia do trânsito (pp. 45-50). Fortaleza: Expressão Gráfica.

Buss, A. H. \& Perry, M. (1992). The aggression questionnaire. Journal of Personality and Social Psychology, 63, 452-459.

Fildes, B. N., Rumbold, G. \& Leening, A. (1991). Speed behaviour and drivers' attitude to speeding. Relatório $\mathrm{n}^{\circ} 16$, Monasch University Accident Research Centre, Victoria, Australia.

Gabany, S. G., Plummer, P. \& Grigg, P. (1997). Why drivers speed: The speeding perception inventory. Journal of Safety Research, 28, 29-36.

Groeger, J. A. \& Rothengatter, J. A. (1998). Traffic psychology and behaviour. Transportation Research Part F, 1, 1-9.
Gouveia, V. V., Chaves, C. M. C. M., Peregrino, R. R., Branco, A. O. C. \& Gonçalves, M. P. (2006). Medindo componentes da agressão: o questionário de Buss-Perry. (Manuscrito submetido à publicação).

Gouveia, V. V., Clemente, M., Vidal, M. A. \& Martinez, E. (2000). Atribución de responsabilidad social: Contexto social y atributos personales del observador. Revista de Psicología Social, 15, 41-51.

Gouveia, V. V., Silva, D. V., Silva, M. P. V., Andrade, M. W. C. L., Silva Filho, S. B. \& Costa, D. M. F. (2002). Atitudes frente à avaliação psicológica para condutores: perspectivas de técnicos, estudantes de Psicologia e usuários. Psicologia: Ciência e Profissão, 22, 50-59.

Harris, M. B. (1996). Aggression, gender, and ethnicity. Aggression and Violent Behavior, 1, 123-146.

Hennessy, D. A. \& Wiesenthal, D. L. (2001). Gender, driver aggression, and driver violence: An applied evaluation. Sex Roles, 44, 661-676.

Lajunen, T., Corry, A., Summala, H. \& Hartley, L. (1997). Impression management and self-deception in traffic behaviour inventories. Personality and Individual Differences, 22, 341353.

Lahey, B. B., Miller, T. L., Schwab-Stone, M., Goodman, S. H., Waldman, I. D., Canino, G., Rathouz, P. J., Dennis, K. D., Bird, H. \& Jensen, P. S. (2000). Age and gender differences in oppositional behavior and conduct problems: A cross-sectional household study of middle childhood and adolescence. Journal of Abnormal Psychology, 109, 488-503.

Lipovetsky, G. (1986). La era del vacío: Ensayos sobre el individualismo contemporáneo. Barcelona: Anagrama.

Marín, L. \& Queiroz, M. S. (2000). A atualidade dos acidentes de trânsito na era da velocidade: uma visão geral. Caderno de Saúde Pública, 16, 7-21.

Miles, D. E. \& Johnson, G. L. (2003). Aggressive driving behaviors: Are there psychological and attitudinal predictors? Transportation Research Part F, 6, 147-161.

Parker, D., Lajunen, T. \& Summala, H. (2002). Anger and aggression among drivers in three European countries. Accident Analysis and Prevention, 34, 229-235.

Rodrigues, A., Jablonski, B. \& Assmar, E. (2000, 20ª ed.). Psicologia social. Petrópolis: Vozes.

Rozestraten, R. J. A. (1988). Psicologia do trânsito: conceitos e processos básicos. São Paulo: Universidade de São Paulo.

Rozestraten, R. J. A. (2003). Violência no trânsito II. Em A. C. R. Tupinambá (Org.), Estudos de psicologia do trânsito (pp. 5161). Fortaleza: Expressão Gráfica.

Uzzell, D. \& Muckle, R. (2005). Simulating traffic engineering solutions to predict changes in driving behaviour. Transportation Research Part F, 8, 311-329.

Recebido em 17/03/06 Aceito em 21/02/07

Endereço para correspondência: Valdiney V. Gouveia, Universidade Federal da Paraíba, CCHLA - Departamento de Psicologia, CEP 58051-900, João Pessoa-PB. E-mail: vvgouveia@ pesquisador.cnpq.br 